\title{
Rapidly rule out acute myocardial infarction by combining copeptin and heart-type fatty acid-binding protein with cardiac troponin
}

Citation for published version (APA):

Jacobs, L. H. J., van Borren, M., Gemen, E., van Eck, M., van Son, B., Glatz, J. F. C., Daniels, M., \& Kusters, R. (2015). Rapidly rule out acute myocardial infarction by combining copeptin and heart-type fatty acid-binding protein with cardiac troponin. Annals of Clinical Biochemistry, 52(5), 550-561. https://doi.org/10.1177/0004563215578189

Document status and date:

Published: 01/09/2015

DOI:

10.1177/0004563215578189

Document Version:

Publisher's PDF, also known as Version of record

Document license:

Taverne

Please check the document version of this publication:

- A submitted manuscript is the version of the article upon submission and before peer-review. There can be important differences between the submitted version and the official published version of record.

People interested in the research are advised to contact the author for the final version of the publication, or visit the DOI to the publisher's website.

- The final author version and the galley proof are versions of the publication after peer review.

- The final published version features the final layout of the paper including the volume, issue and page numbers.

Link to publication

\footnotetext{
General rights rights.

- You may freely distribute the URL identifying the publication in the public portal. please follow below link for the End User Agreement:

www.umlib.nl/taverne-license

Take down policy

If you believe that this document breaches copyright please contact us at:

repository@maastrichtuniversity.nl

providing details and we will investigate your claim.
}

Copyright and moral rights for the publications made accessible in the public portal are retained by the authors and/or other copyright owners and it is a condition of accessing publications that users recognise and abide by the legal requirements associated with these

- Users may download and print one copy of any publication from the public portal for the purpose of private study or research.

- You may not further distribute the material or use it for any profit-making activity or commercial gain

If the publication is distributed under the terms of Article $25 \mathrm{fa}$ of the Dutch Copyright Act, indicated by the "Taverne" license above, 


\title{
Rapidly rule out acute myocardial infarction by combining copeptin and heart-type fatty acid-binding protein with cardiac troponin
}

\author{
Leo HJ Jacobs' ',*, Marcel van Borren',*, Eugenie Gemen', Martijn van Eck², Bas van \\ Son ${ }^{2}$, Jan FC Glatz ${ }^{3}$, Marcel Daniels ${ }^{2}$ and Ron Kusters ${ }^{1,4}$
}

\begin{abstract}
Background: The rapid exclusion of acute myocardial infarction in patients with chest pain can reduce the length of hospital admission, prevent unnecessary diagnostic work-up and reduce the burden on our health-care systems. The combined use of biomarkers that are associated with different pathophysiological aspects of acute myocardial infarction could improve the early diagnostic assessment of patients presenting with chest pain.

Methods: We measured cardiac troponin I, copeptin and heart-type fatty acid-binding protein concentrations in 584 patients who presented to the emergency department with acute chest pain. The diagnostic performances for the diagnosis of acute myocardial infarction and NSTEMI were calculated for the individual markers and their combinations. Separate calculations were made for patients presenting to the emergency department $<3 \mathrm{~h}, 3-6 \mathrm{~h}$ and $6-12 \mathrm{~h}$ after chest pain onset.

Results: For ruling out acute myocardial infarction, the net predictive values $(95 \% \mathrm{Cl})$ of cardiac troponin I, copeptin and heart-type fatty acid-binding protein were $90.4 \%$ (87.3-92.9), 84\% (79.8-87.6) and 87\% (83.5-90), respectively. Combining the three biomarkers resulted in a net predictive value of $95.8 \%(92.8-97.8)$. The improvement was most pronounced in the early presenters $(<3 \mathrm{~h})$ where the combined net predictive value was $92.9 \%(87.3-96.5)$ compared to 84.6\% (79.4-88.9) for cardiac troponin I alone. The area under the receiver operating characteristic for the triple biomarker combination increased significantly $(P<0.05)$ compared to that of cardiac troponin I alone $(0.880$ [0.833$0.928]$ vs. 0.840 [0.78I-0.898], respectively).

Conclusions: Combining copeptin, heart-type fatty acid-binding protein and cardiac troponin I measurements improves the diagnostic performance in patients presenting with chest pain. Importantly, in patients who present early $(<3 \mathrm{~h})$ after chest pain onset, the combination improves the diagnostic performance compared to the standard cardiac troponin I measurement alone.
\end{abstract}

\section{Keywords}

Acute myocardial infarction, copeptin, heart-type fatty acid-binding protein, troponin

Accepted: 23rd February 2015

\footnotetext{
'Laboratory for Clinical Chemistry and Hematology, Jeroen Bosch Hospital, 's-Hertogenbosch, The Netherlands

${ }^{2}$ Department of Cardiology, Jeroen Bosch Hospital, 's-Hertogenbosch, The Netherlands

${ }^{3}$ Department of Genetics and Cell Biology, Cardiovascular Research Institute Maastricht, Maastricht University, Maastricht, The Netherlands
}

\footnotetext{
${ }^{4}$ Department of Health Technology and Services Research, University of Twente, Enschede, The Netherlands

*Contributed equally to this work.

Corresponding author:

Ron Kusters, Laboratory for Clinical Chemistry and Hematology, Jeroen Bosch Hospital, Henri Dunantstraat I, PO box 90153, 's-Hertogenbosch, The Netherlands.

Email: r.kusters@jbz.nl
} 


\section{Introduction}

Acute myocardial infarction (AMI) remains one of the most common causes of death in the western world. In the USA alone, over 7.6 million people have suffered from an AMI and another 7.9 million have had angina pectoris. ${ }^{1}$ The ability to rapidly and accurately distinguish AMI from other causes of chest pain is crucial to the initiation of effective therapeutic strategies. ${ }^{2}$ Moreover, because only approximately one in five patients who present to the emergency department (ED) with symptoms of AMI are actually diagnosed with $\mathrm{AMI},{ }^{3-5}$ an accelerated rule out can free up valuable time from health-care providers and reduce the burden on health-care systems.

As the clinical symptoms associated with AMI are often non-specific, the diagnosis of AMI relies strongly on electrocardiography and on measurements of biomarkers that are associated with cardiac ischemia. ${ }^{6,7}$ The most prominent of these biomarkers are the cardiac troponins (cTns), which have become the gold standard for the detection of myocardial injury. ${ }^{7}$ According to current international guidelines, the diagnosis of AMI (in a clinical setting of suspected AMI) can largely be made based on a rise and/or fall of cTn values. Hereby, the absence of a cTn elevation at the time of presentation does not rule out an AMI, necessitating the need for a second cTn measurement 3-6h later. ${ }^{7}$ A biomarker or combination of biomarkers with the ability to safely rule out AMI in a shorter timeframe could reduce the admission time for the majority of patients presenting to the ED with acute chest pain. The subsequent reduction in admission time is likely to improve the allocation of resources and decrease health-care costs. ${ }^{8}$

Over the years, a number of protein biomarkers have been suggested to improve and/or accelerate the diagnosis of AMI. An example is the small cytosolic protein heart-type fatty acid-binding protein (H-FABP), which, similar to $\mathrm{cTn}$, is released upon cardiomyocyte damage. ${ }^{9}$ Recent meta-analyses seem to suggest that the diagnostic performance of H-FABP does not exceed that of $\mathrm{cTn},{ }^{10}$ but that a combination of the two may improve the diagnostic effectiveness. ${ }^{11}$ Another promising biomarker, related to a different pathophysiological aspect of AMI, is copeptin. The release of copeptin, a stable precursor of arginine-vasopressin, mirrors that of arginine-vasopressin but as a result of its longer half-life, it is more suitable to assess endogenous stress levels. ${ }^{12}$ Because copeptin is released in response to changes in hemodynamic stress, it may show a more pronounced release during the first hours after AMI (compared to markers of myocardial damage) and improve the early diagnosis of AMI. Studies to date have indeed shown that the addition of copeptin to cTn measurements can improve the early diagnosis of AMI. ${ }^{3,4}$ However, it should be noted that the improved diagnostic performance is debated when more sensitive cTn assays are used. ${ }^{13,14}$

In this report, we investigate whether a combination of biomarkers that coincide with different pathophysiological aspects of AMI can improve the diagnostic process in the early assessment of patients presenting with chest pain. To this aim, we examined whether the addition of copeptin and/or H-FABP on top of cTnI measurements can improve the early rule out of AMI and NSTEMI in patients presenting to the ED with chest pain and obviate the need for serial sampling.

\section{Materials and methods}

\section{Study design and population}

From September 2010 to May 2011, we included all consecutive ( $>18$ year old) patients presenting to the ED with chest pain within the first $12 \mathrm{~h}$ after the onset of symptoms. For patients who presented more than once to the ED during the inclusion period, only the first occurrence was included in our study. Blood samples were obtained within $30 \mathrm{~min}$ after arrival at the ED. The investigational procedures involved in this study have been approved by the local medical ethical review committee (METC Brabant) and comply with the declaration of Helsinki. According to the local medical ethical review committee, the Dutch Medical Research Involving Human Subjects Act (WMO) did not apply to our study, and no formal informed consent was mandatory.

\section{Diagnostic procedures and final diagnosis}

All participants underwent an initial clinical assessment that included a physical examination, electrocardiography, review of patient history and standard blood tests. AMI was diagnosed according to the definition of myocardial infarction. ${ }^{7}$ In brief, AMI was diagnosed when clinical signs of myocardial ischemia were associated with a rising and/or falling pattern of the cTnI concentration with at least one value above the 99th percentile cut-off value. The diagnosis for unstable angina pectoris was made in patients with clinical symptoms of acute coronary syndrome in whom cTnI concentrations were normal (did not show a rising or falling pattern). Further predefined diagnostic categories included cardiac but not coronary disease (e.g. pericarditis or tachyarrhythmias) and noncardiac causes (e.g. acid reflux). If AMI was ruled out but no conclusive diagnosis could be established or was sought, the symptoms were classified as being of unknown origin. To determine the final diagnosis for each patient, both a cardiology resident and 
one independent cardiologist reviewed all available medical records (blinded for H-FABP and copeptin results).

\section{Biochemical analysis}

Routine laboratory parameters, including cTnI, were measured directly following flebotomy on admission. Additionally, plasma samples for copeptin and $\mathrm{H}$ FABP measurements were aliquoted and stored at $-20^{\circ} \mathrm{C}$. The $\mathrm{cTnI}$ measurements were performed using the cTnI assay for the Dimension Vista ${ }^{\circledR} 1500$ System (Siemens Healthcare Diagnostics). This assay has a measuring range from $15 \mathrm{ng} / \mathrm{L}$ to $40,000 \mathrm{ng} / \mathrm{L}$ and a $10 \%$ coefficient limit of variation of $40 \mathrm{ng} / \mathrm{L}$, as specified by the manufacturer. The diagnostic cut-off value for the cTnI assay is set at $45 \mathrm{ng} / \mathrm{L}$ (99th percentile value). Copeptin was measured using the BRAHMS Copeptin Kryptor assay. According to manufacturer data, the limit of detection was estimated at $4.8 \mathrm{pmol} /$ $\mathrm{L}$, and the limit of quantitation (estimated in accordance with CLSI EP17-A guideline) is $14.1 \mathrm{pmol} / \mathrm{L}$. The diagnostic cut-off value for copeptin is set at $14 \mathrm{pmol} / \mathrm{L}$, based on previous literature. ${ }^{4,15} \mathrm{H}-\mathrm{FABP}$ was measured using a direct non-competitive enzyme-linked immunosorbent assay, as described previously. ${ }^{16,17}$ The detection limit for this assay is $0.25 \mathrm{ng} / \mathrm{mL}$, with a detection range up to $32 \mathrm{ng} / \mathrm{mL}$. The coefficients of variation at 5 , 12 and $25 \mathrm{ng} / \mathrm{mL}$ is $4 \%, 5 \%$ and $7 \%$, respectively. The diagnostic cut-off value was set at $4 \mathrm{ng} / \mathrm{mL} .{ }^{17}$

\section{Statistical methods}

Continuous variables are expressed as mean \pm standard deviation (SD) or median interquartile range (IQR). Categorical data are presented as numbers and percentages. The categorical variables were compared using the Pearson chi-square test, and continuous variables were compared using the Mann-Whitney $U$ test. The diagnostic sensitivity, specificity, positive predictive value (PPV) and negative predictive value (NPV) for the individual biomarkers and their combinations were assessed using the cut-off levels described above. For the combinations, a result was considered positive if any of the markers had a positive result (i.e. above the respective diagnostic cut-off value). Receiver operating characteristic (ROC) curves, based on continuous biomarker measurements, were constructed for the individual biomarkers and their combinations. Logistic regression was used to combine the biomarker measurements. The areas under the ROC curves (AUC) were compared as described by DeLong et al. ${ }^{18}$ All hypotheses testing was two-tailed, and $P$ values $<0.05$ were considered statistically significant. Statistical analyses were performed using IBM SPSS Statistics version
20, MedCalc for Windows version 12.7.8 and Analyseit for Microsoft Excel version 2.26.

\section{Results \\ Characteristics of patients}

A total of 584 patients were enrolled in our study. The baseline characteristics are shown in Table 1. Within our population, $141(24 \%)$ patients were diagnosed with AMI, of which 46 ( $8 \%$ of the entire cohort) were classified as ST elevation myocardial infarction (STEMI) and $95(16 \%)$ as NSTEMI. Unstable angina pectoris was diagnosed in $33(6 \%)$ cases, cardiac, noncoronary disease in $60(10 \%)$, non-cardiac causes in 126 $(22 \%)$ and unknown origin in $224(38 \%)$ patients. The median time from chest pain onset $(\mathrm{CPO})$ to presentation at the ED was $180 \mathrm{~min}(\mathrm{IQR}=108-312)$.

\section{Biomarker concentrations}

As shown in Table 1, patients who were diagnosed with AMI had significantly higher median (IQR) concentrations of cTnI, copeptin and H-FABP than those who were not diagnosed with AMI $(123 \mathrm{ng} / \mathrm{L}[33-592 \mathrm{ng} / \mathrm{L}]$ vs. $20 \mathrm{ng} / \mathrm{L}[20-20 \mathrm{ng} / \mathrm{L}]$ for $\mathrm{cTnI}, 19.7 \mathrm{pmol} / \mathrm{L}[9.5-$ $73.4 \mathrm{pmol} / \mathrm{L}]$ vs. $8.6 \mathrm{pmol} / \mathrm{L}[5.1-16.5 \mathrm{pmol} / \mathrm{L}]$ for copeptin and $4.7 \mathrm{ng} / \mathrm{mL}[3.1-10.2 \mathrm{ng} / \mathrm{L}]$ vs. $2.4 \mathrm{ng} / \mathrm{mL}[1.8$ $3.1 \mathrm{ng} / \mathrm{mL}$ for H-FABP, $P<0.001$ for all comparisons). Patients with STEMI had higher copeptin and H-FABP concentrations than those with NSTEMI (copeptin: $75.4 \mathrm{pmol} / \mathrm{L}$ [19.7-171.1 pmol/L] vs. $13.5 \mathrm{pmol} / \mathrm{L}$ [7.6$42.7 \mathrm{pmol} / \mathrm{L}], P<0.001$ and H-FABP: $7.2 \mathrm{ng} / \mathrm{mL}[3.6-$ $13.8 \mathrm{ng} / \mathrm{mL}]$ vs. $4.4 \mathrm{ng} / \mathrm{mL}[2.7-9.5 \mathrm{ng} / \mathrm{mL}], P=0.021)$. The difference in the cTnI concentration did not reach statistical significance $(209 \mathrm{ng} / \mathrm{L}$ [34-988 ng/L] vs. $105 \mathrm{ng} / \mathrm{L}[32-343 \mathrm{ng} / \mathrm{L}], P=0.225$ ).

The biomarker concentrations varied depending on the delay between CPO and presentation at the ED. Figure 1 visualizes the median cTnI, copeptin and $\mathrm{H}$ FABP concentrations for AMI (both STEMI and NSTEMI) and non-AMI patients presenting between 0 and $3 \mathrm{~h}, 3$ and $6 \mathrm{~h}$, and 6 and $12 \mathrm{~h}$. Results for the patients with AMI are also shown separately for STEMI and NSTEMI. The differences in biomarker concentrations were most pronounced in patients diagnosed with STEMI. Within this group, the median cTnI values were lowest in those presenting to the ED in the first $3 \mathrm{~h}$ after onset of symptoms (57 ng/L [24-741 ng/ L]) and increased in those presenting 3-6h $(453 \mathrm{ng} / \mathrm{L}$ [397-988 ng/L]) and $6-12 \mathrm{~h}$ after onset of symptoms (5296 ng/L [3874-6018 ng/L]). A similar trend could be witnessed for H-FABP $(5.1 \mathrm{ng} / \mathrm{mL}$ [3.5-9.2], $8.1 \mathrm{ng} /$ $\mathrm{mL}[6.1-29.0 \mathrm{ng} / \mathrm{mL}]$ and $29.3 \mathrm{ng} / \mathrm{mL}[17.3-34.2 \mathrm{ng} / \mathrm{mL}]$ in STEMI patients presenting to the ED $0-3 \mathrm{~h}, 3-6 \mathrm{~h}$ 


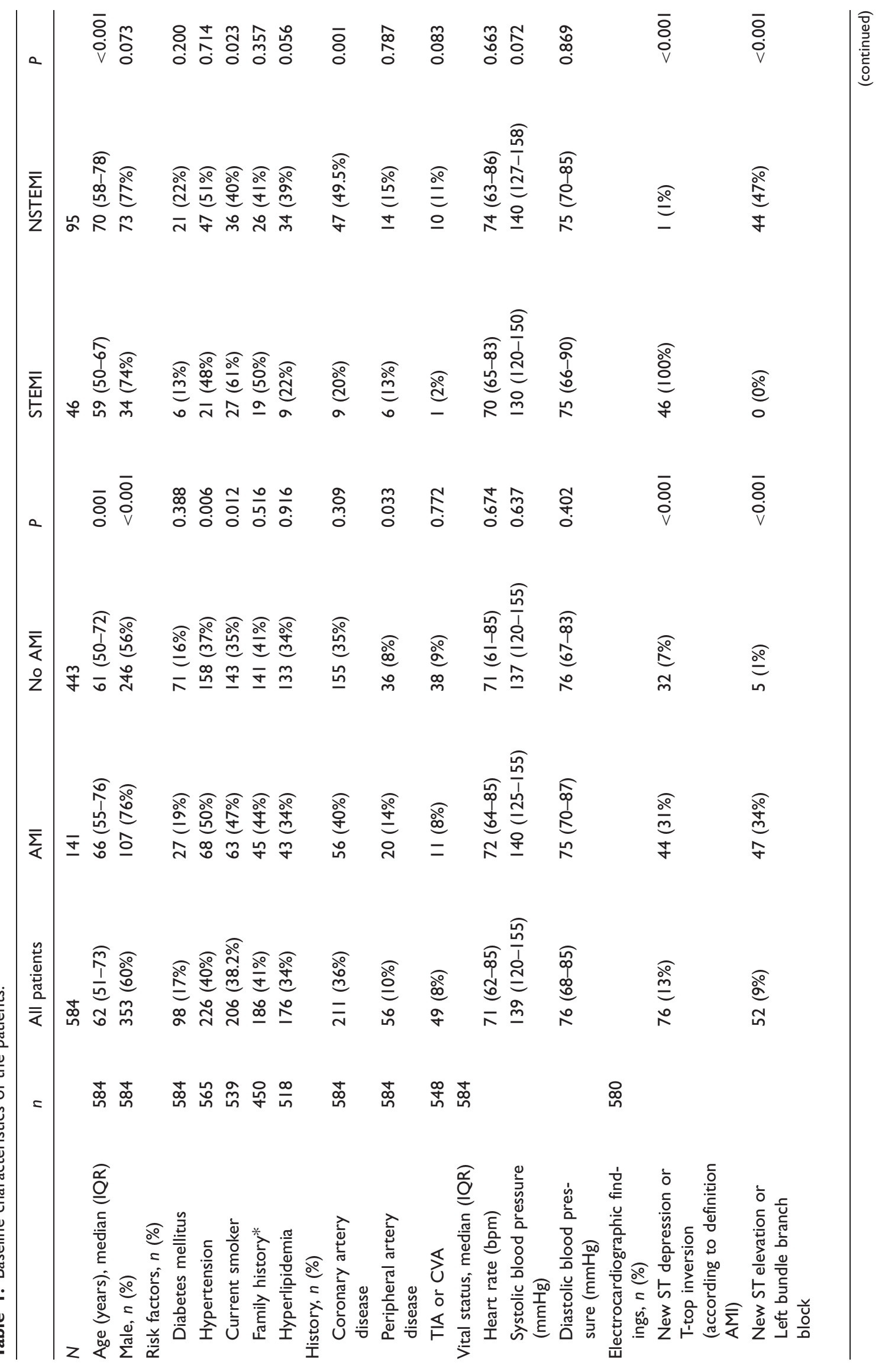



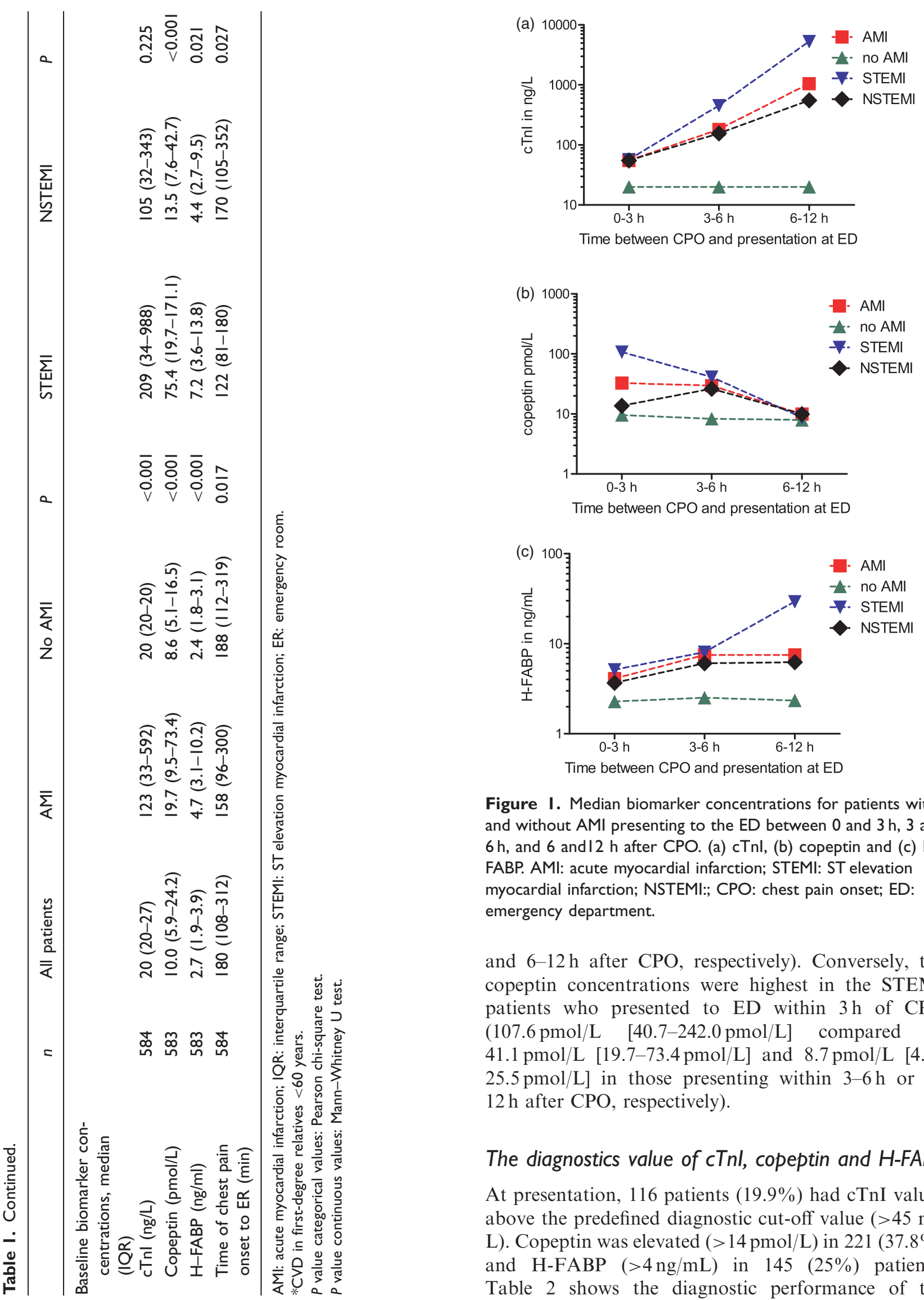

Figure I. Median biomarker concentrations for patients with and without AMI presenting to the ED between 0 and $3 \mathrm{~h}, 3$ and $6 \mathrm{~h}$, and 6 and $12 \mathrm{~h}$ after CPO. (a) cTnl, (b) copeptin and (c) HFABP. AMI: acute myocardial infarction; STEMI: ST elevation myocardial infarction; NSTEMI:; CPO: chest pain onset; ED: emergency department.

and $6-12 \mathrm{~h}$ after $\mathrm{CPO}$, respectively). Conversely, the copeptin concentrations were highest in the STEMI patients who presented to ED within $3 \mathrm{~h}$ of $\mathrm{CPO}$ $(107.6 \mathrm{pmol} / \mathrm{L} \quad[40.7-242.0 \mathrm{pmol} / \mathrm{L}]$ compared to $41.1 \mathrm{pmol} / \mathrm{L}[19.7-73.4 \mathrm{pmol} / \mathrm{L}]$ and $8.7 \mathrm{pmol} / \mathrm{L}$ [4.6$25.5 \mathrm{pmol} / \mathrm{L}]$ in those presenting within $3-6 \mathrm{~h}$ or $6-$ $12 \mathrm{~h}$ after $\mathrm{CPO}$, respectively).

\section{The diagnostics value of cTnl, copeptin and H-FABP}

At presentation, 116 patients $(19.9 \%)$ had $\mathrm{cTnI}$ values above the predefined diagnostic cut-off value ( $>45 \mathrm{ng} /$ L). Copeptin was elevated ( $>14 \mathrm{pmol} / \mathrm{L})$ in $221(37.8 \%)$ and H-FABP $(>4 \mathrm{ng} / \mathrm{mL})$ in $145(25 \%)$ patients. Table 2 shows the diagnostic performance of the 


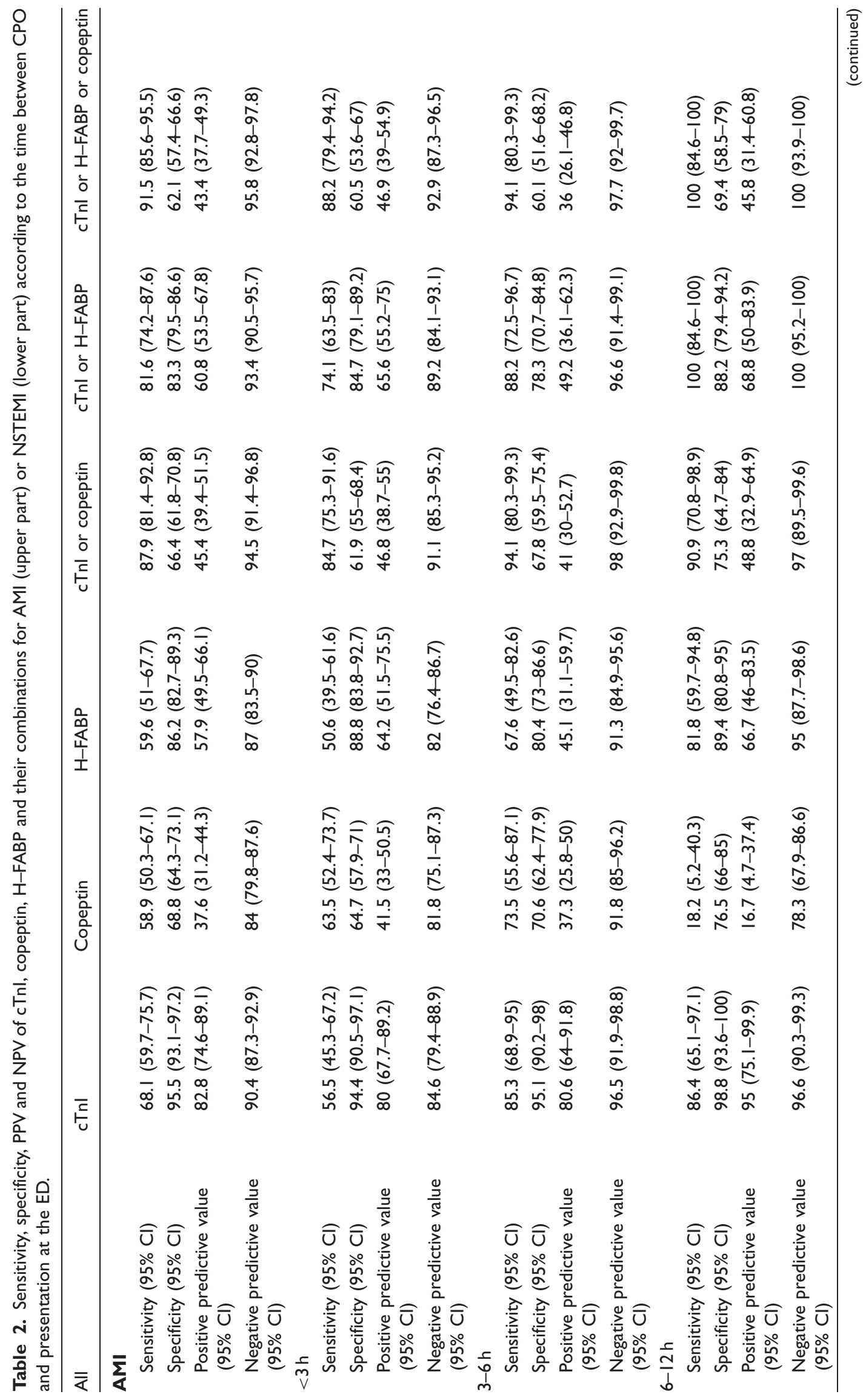




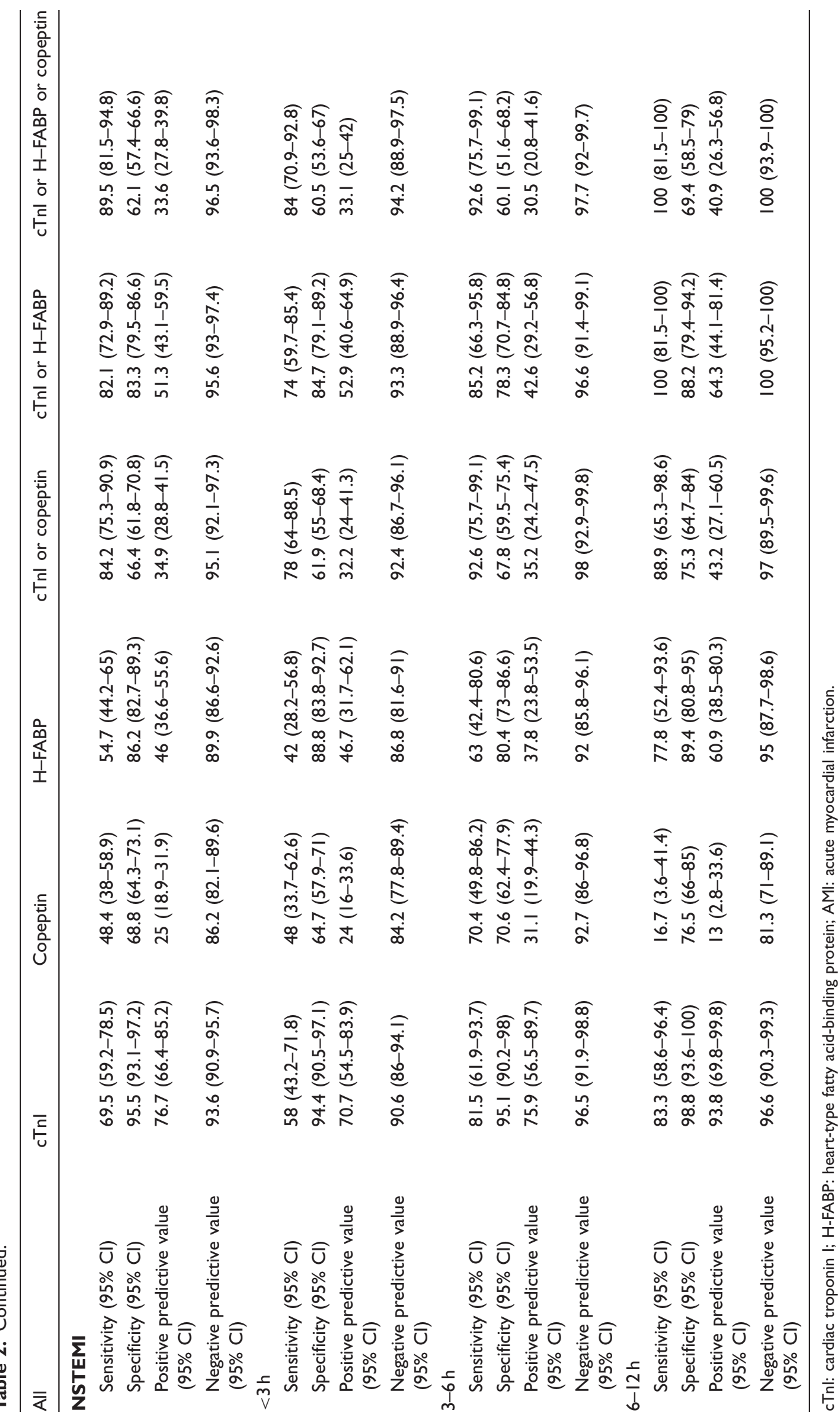


biomarkers and their combinations when using the predefined cut-off values. Sensitivity, specificity as well as the PPVs and NPVs are shown for both AMI patients and for NSTEMI patients separately. Moreover, the diagnostic performances were calculated according to the time intervals between $\mathrm{CPO}$ and presentation at the ED. As the general trends for the diagnostic performance for the diagnosis of AMI and NSTEMI were similar, we will limit the detailed description of the results below mainly to those for AMI. As can be seen in Table 2, the NPV for cTnI was lowest in patients presenting to the ED in the first $3 \mathrm{~h}(\mathrm{NPV}=84.6 \%[79.4$ $88.9]$ ), increasing to $96.5 \%(91.9-98.8)$ and $96.6 \%$ (90.3-99.3) in those presenting between 3 and $6 \mathrm{~h}$, and 6 and $12 \mathrm{~h}$, respectively. For H-FABP, the improvement in NPV with increasing delay between CPO and presentation was even more pronounced (82\% [76.486.7], 91.3\% [84.9-95.6] and 95\% [87.7-98.6] for those presenting $<3 \mathrm{~h}, 3-6 \mathrm{~h}$ and $6-12 \mathrm{~h}$, respectively). For copeptin, the highest NPV was found in the subjects who presented between 3 and $6 \mathrm{~h}(91.8 \%$ [85-96.2]) and, interestingly, was higher in the early $(<3 \mathrm{~h})$ presenters $(81.8 \%$ [75.1-87.3]) than in those arriving at the ED between 6 and $12 \mathrm{~h}$ (78.4\% [67.9-86.6]).

In the overall study population, any combination of biomarkers resulted in an increased NPV compared to the individual biomarkers. The highest NPV was obtained when cTnI, copeptin and H-FABP measurements were combined, resulting in an overall NPV of $95.8 \%$ (92.8-97.8). Separate calculations for each of the time intervals between CPO and arrival at ED indicate that the combination of biomarkers increases the NPV for each of the investigated time intervals. The improved NPV was most pronounced in the early presenters $(<3 \mathrm{~h})$ in whom the NPV for the combination of the three markers is $92.9 \%(87.3-96.5)$ compared to $84.6 \%$ (79.4-88.9) for cTnI alone. None of the combinations in the $<3 \mathrm{~h}$ group, however, generates a NPV that exceeds the NPV of cTnI in the 3-6h group.

To assess the overall diagnostic performance of the biomarkers under investigation, we constructed ROC curves. Figure 2 shows the ROC curves for the biomarkers under investigation for the overall cohort both for diagnosis of AMI (Figure 2(a)) and for diagnosis of NSTEMI (Figure 2(b)). The area under the curve (AUC) is highest for cTnI (AUC [95\% $\mathrm{CI}]=0.882[0.842-0.921])$ and is significantly higher than that of H-FABP (AUC $=0.812[0.768-0.856]$; $P=0.003)$ or copeptin (AUC $=0.707 \quad[0.657-0.757]$; $P<0.001)$. The combination of cTnI with H-FABP significantly increases the diagnostic accuracy compared to $\mathrm{cTnI}$ alone $(\mathrm{AUC}=0.909$ [0.876-0.942]; $P=0.030$ ). Combining $\mathrm{cTnI}$ with copeptin similarly increased the diagnostic accuracy $\quad(\mathrm{AUC}=0.909 \quad$ [0.876-0.941]; $P=0.035)$. Combining $\mathrm{cTnI}$ with both $\mathrm{H}-\mathrm{FABP}$ and copeptin measurements (AUC of combination $=0.916$ [0.885-0.946]) does not significantly improve the AUC compared to the combination of cTnI and H-FABP alone $(P=0.483)$ or the combination of $\mathrm{cTnI}$ and copeptin alone $(P=0.166)$.

Exclusion of STEMI patients in our analyses generates the results shown in Figure 2(b). For the diagnosis of NSTEMI, the AUC for $\mathrm{cTnI}$ (AUC $=0.876[0.827$ 0.925]) is significantly higher than that of H-FABP (0.779 [0.724-0.835]; $P=0.002)$ and copeptin $(0.637$ [0.577-0.698]; $P<0.001)$. Combining cTnI with $\mathrm{H}-$ FABP (combined AUC $=0.903 \quad[0.863-0.943]$ ) improved the diagnostic accuracy compared to cTnI alone, although the comparison of the AUC's failed to reach statistical significance $(P=0.054)$. The
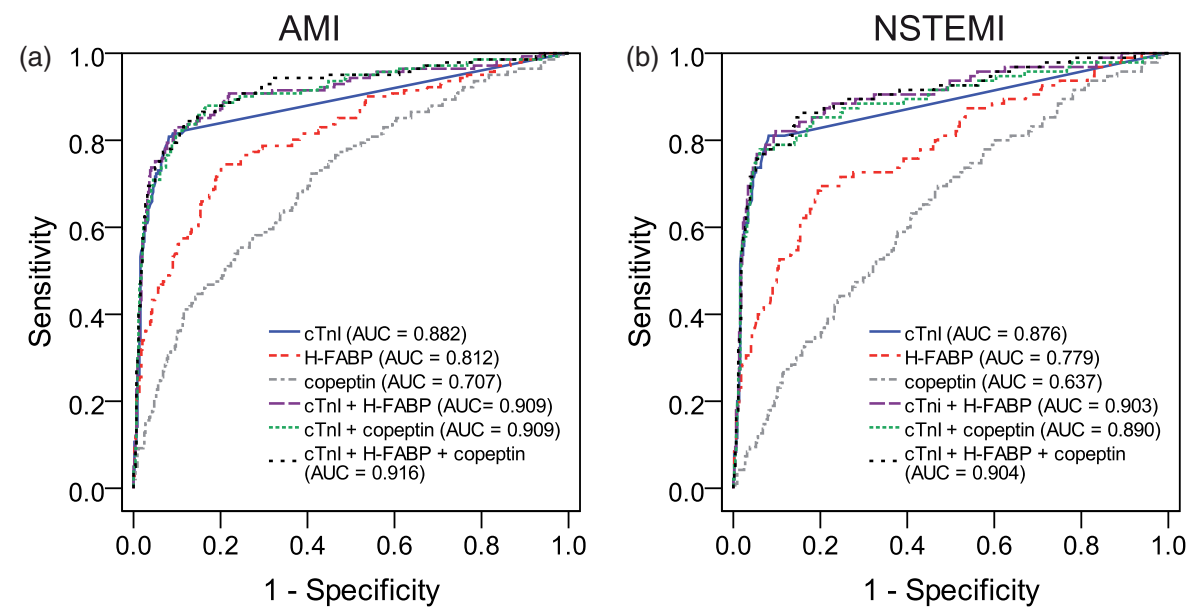

Figure 2. ROC curves for the biomarkers under investigation. (a) AMI (= STEMI+NSTEMI) and (b) NSTEMI. cTnl: cardiac troponin I; H-FABP: heart-type fatty acid-binding protein; AUC: area under the curve; AMI: acute myocardial infarction; STEMI: ST elevation myocardial infarction. 

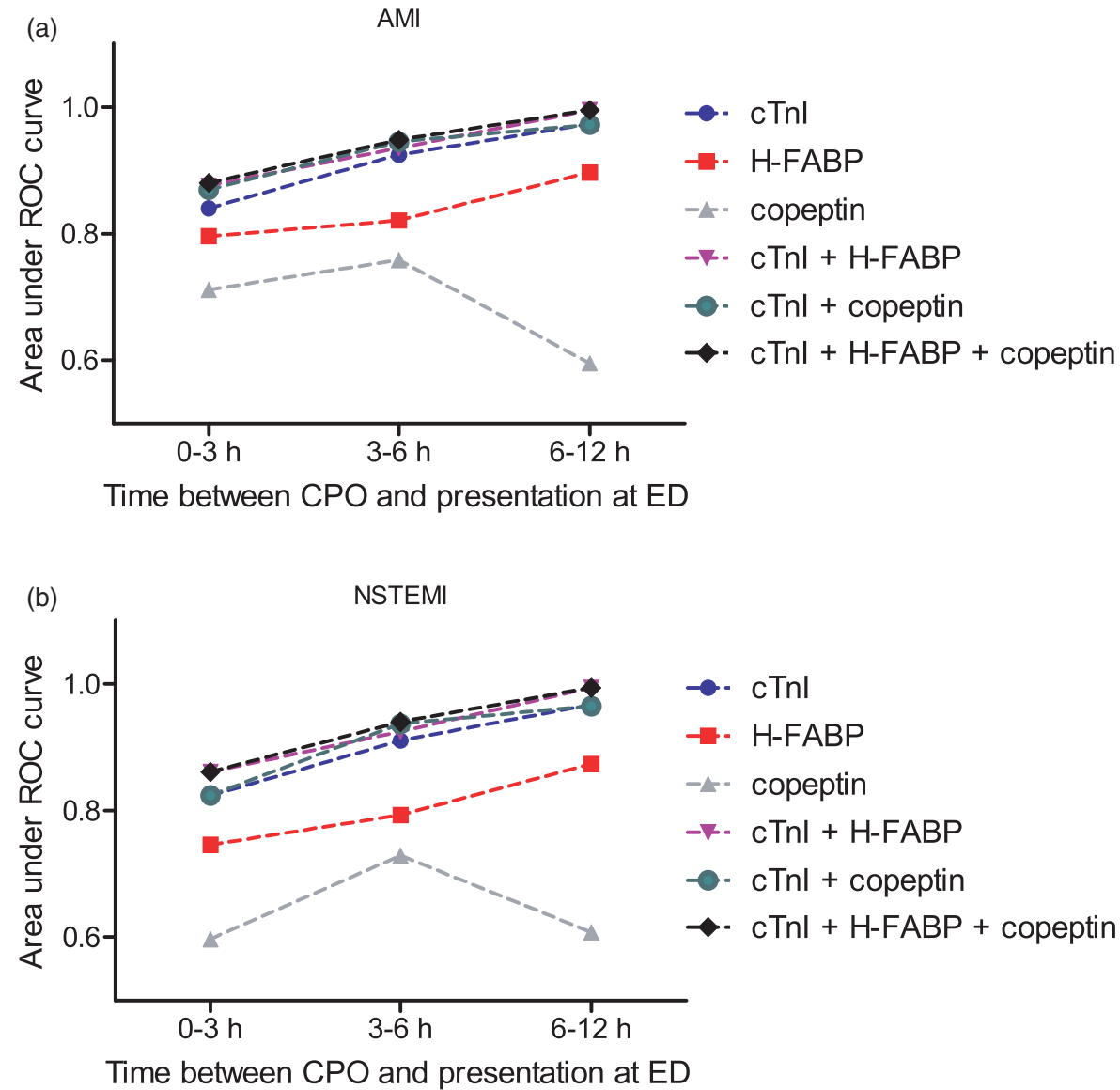

Figure 3. AUC's for each of the biomarkers and their combinations according to time between CPO and presentation at ED. (a) AMI and (b) NSTEMI. cTnl: cardiac troponin I; H-FABP: heart-type fatty acid-binding protein; ROC: receiver operating characteristic; AMI: acute myocardial infarction; CPO: chest pain onset; ED: emergency department.

combination of cTnI with copeptin (combined AUC $=0.890 \quad[0.846-0.934])$ did not significantly improve the diagnostic accuracy for NSTEMI $(P=0.267)$. The combination of cTnI with both copeptin and H-FABP did, however, result in a significantly higher AUC (0.904 [0.864-0.943]; $P=0.040$ ).

Separate analysis of the diagnostic accuracy of the biomarkers and their combinations was made for the patients presenting to the $\mathrm{ED}<3 \mathrm{~h}, 3-6 \mathrm{~h}$ and $6-12 \mathrm{~h}$. Figure 3 visualizes the AUC for the diagnosis of AMI (Figure 3(a)) and NSTEMI (Figure 3(b)) for each of the biomarkers and their combinations for the patients presenting at different time points after CPO. The diagnostic accuracy increases with the time from CPO to ED for all biomarkers and their combinations, with the exception of copeptin, which shows a decrease in the AUC after $6 \mathrm{~h}$ (Figure 3). In general, the combination of cTnI with H-FABP and/or copeptin results in higher AUCs than for cTnI alone. The increase in AUC was, however, only statistically significant for the combination of cTnI with H-FABP and copeptin in the patients who presented within the first $3 \mathrm{~h}$ (cTnI
AUC $=0.840[0.781-0.898]$ vs. the triple combination $\mathrm{AUC}=0.880$ [0.833-0.928]; $P=0.037$ ).

The diagnostic accuracies for NSTEMI resemble those in AMI (Figure 3(b)). Again, only copeptin shows a decrease in the AUC in those presenting $6 \mathrm{~h}$ after $\mathrm{CPO}$, whereas the other markers and their combinations show a gradual increase in AUC with increasing duration between $\mathrm{CPO}$ and presentation at the ED. Combining cTnI with copeptin and H-FABP measurements increases the AUC compared to cTnI alone in each of the investigated time-intervals, although the increases are not statistically significant. The increase in $\mathrm{AUC}$ is most pronounced for those presenting in the first $3 \mathrm{~h}$ (cTnI AUC $=0.823[0.745-0.901]$ vs. the triple combination $\mathrm{AUC}=0.861[0.797-0.925], P=0.1134)$.

\section{Discussion}

This study investigated the diagnostic value of the combined measurement of cTnI, copeptin and H-FABP and their potential to improve the diagnostic evaluation of patients presenting to the emergency room with chest 
pain. We report the following findings: (1) The addition of copeptin and/or H-FABP to cTnI increases the diagnostic sensitivity and NPV compared to cTnI alone. This increase is seen for both the rule out of AMI and (after exclusion of STEMI patients) for the rule out of NSTEMI. (2) The most impressive gains in sensitivity and in NPV are found in patients who present early $(<3 \mathrm{~h})$ to the ED after CPO. (3) The overall diagnostic performance for diagnosing AMI can be significantly improved by combining cTnI with H-FABP and/ or copeptin measurements. This added diagnostic performance holds true after the exclusion of STEMI patients, albeit less pronounced. For NSTEMI, the increase in AUC generated by combining H-FABP and $\mathrm{cTnI}$ just failed to reach statistical significance $(P$ $=0.054)$, but the combination of all three markers resulted in a significant improvement compared to cTnI alone $(P=0.040)$. (4) The diagnostic accuracy increases with the delay between CPO and presentation at the ED for all biomarkers and their combinations, with the exception of copeptin, which shows a decrease in the AUC after 6h. (5) While the diagnostic evaluation of the chest pain patients in our study was improved markedly by combining biomarkers, the NPVs remain inadequate to rule out AMI (or NSTEMI) based only on admission measurements.

Comparison of our results with those in literature is hampered by differences in methodology among published studies. For example, some studies have investigated the diagnostic potential for ruling out AMI, whereas others limited their analysis to NSTEMI. In this report, we performed separate calculations for both AMI and NSTEMI. Furthermore, reviewing results from published work is hampered by the use of different cTn assays in the various studies. To date, there is no other report on the use of the Vista cTnI assay in combination with copeptin or H-FABP. Nevertheless, some interesting conclusions can be drawn from a comparison with other studies.

For convenience, we will first compare our data with combined results of 15 studies (8470 patients) on cTn and copeptin, which have recently been generated in a meta-analysis by Raskovalova et al. ${ }^{19}$ This meta-analysis reveals some interesting findings, for example, the hs-cTnT assay has a higher diagnostic sensitivity (91\%) than the Siemens TnI-Ultra assay (79\%). The increase in diagnostic sensitivity as a results of adding copeptin measurements to $\mathrm{cTnI}$ is $14 \%(6-21)$ in the meta-analysis, which is comparable to the $19.8 \%$ increase that we find in our study. ${ }^{19}$ Two very recent reports, not included in the meta-analysis, that investigated the added value of copeptin on top of cTnI in the evaluation of chest pain patients have shown mixed results. The first study by Maisel et al. ${ }^{15}$ shows clear advantages of adding copeptin to cTnI measurement and even suggests that the addition of copeptin has the potential to rule out AMI in $58 \%$ of patients with a baseline measurement. The second study, by Collinson et al., ${ }^{20}$ however, does not show an added diagnostic value for copeptin measurements. To date, most studies seem to suggest that the addition of copeptin to cTnI measurements improves the early rule out of AMI in patients with chest pain. Importantly, the majority of data was gathered using contemporary cTn assays, and studies using high sensitivity cTn assays fail to show a diagnostic advantage in adding copeptin to cTn measurements. ${ }^{13,14}$ It will be interesting to see whether the potential value of copeptin on top of cTn can be improved by more sensitive copeptin assays. A recent study by Sebbane et al. ${ }^{21}$ indeed shows an added diagnostic value of ultrasensitive copeptin measurements on top of high-sensitivity cTnT measurements.

Combining cTnI and H-FABP revealed a clear increase in the diagnostic sensitivity compared to cTnI alone (at the expense of specificity). The improved sensitivity is in agreement with other reports, which also find an added diagnostic value for the combination of cTn and H-FABP. A review by Lippi et al. ${ }^{11}$ (totalling results for 2735 patients) shows a significant increase in both AUC and sensitivity for the combination of cTn and H-FABP compared to cTn alone. More recent studies, not included in this review, that use various highly sensitive cTn assays show mixed results. For example, a study in 343 patients using both a contemporary and a sensitive $\mathrm{cTnI}$ assay showed a significant increase in the AUCs for the combination with H-FABP with the contemporary (Centaur, cTnI Siemens) assay but not with the highly sensitive assay (TnI-Ultra, Siemens). ${ }^{22}$ Similarly, Reiter et al. ${ }^{23}$ showed no added diagnostic value for H-FABP on top of hs-cTnT measurements. On the other hand, Keller et al. ${ }^{3}$ showed a combined sensitivity of $85 \%$ compared to $73 \%$ for hs-cTnI (Architect STAT High sensitive troponin, Abbott Diagnostics) alone. These last results are remarkably similar to those in our study, in which the sensitivity of the combination was $82 \%$ (for both AMI and NSTEMI) compared to $68 \%(69.5 \%$ for NSTEMI) for cTnI alone.

Within our study, we also investigated the added value of combining both copeptin and H-FABP measurements with cTnI. This triple combination only marginally improved the diagnostic power on top of the double combinations, although the increase in AUC for the triple combination in NSTEMI patients reaches statistical significance, whereas that of the double combinations did not.

While the overall diagnostic performance seems to increase, it is important to note that the combination of biomarkers greatly decreases the PPV compared to cTnI alone. In fact, as can be seen in Table 2, the decrease in PPV is far greater than the increase in 
NPV (e.g. for AMI, the PPV and NPV for cTnI in the overall population are 82.8 and 90.4 compared to 43.4 and 95.8 for the triple biomarker combination). As such, the effects of the reduced PPV may outweigh the benefits of the increased NPV.

In addition to the changes in specificity, it should be noted that the demand for a short turnaround time limits the use of three separate assays at the ED or coronary care unit. Attempts of manufacturers to produce diagnostic methods to measure relevant markers simultaneously may provide improvements on this issue. Nonetheless, future investigations are needed to assess the feasibility and practicality (e.g. available laboratory space, necessary training for medical/ laboratory personnel, etc.) of measuring and combining three separate biomarkers.

A second limitation pertains to the size of our study population. Some of the increases in the diagnostic power, particularly those in the early hours of CPO, failed to reach statistical significance (by very small numbers). Even though our population is of moderate size, a larger population would improve the statistical power of our analysis. A third limitation of our study is the absence of cTn measurements with both cTnI and cTnT assays. We only measured cTn concentrations with a cTnI assay and do not know whether our findings hold true for cTnT or not. Based on literature findings, the added value of copeptin and H-FABP is likely to hold true for both cTnI and cTnT, but a direct comparison in this study would have been of interest.

In conclusion, the addition of copeptin and/or $\mathrm{H}$ FABP to cTnI improves the early diagnostic assessment of patients presenting with symptoms of chest pain. While the current increase in diagnostic power is insufficient to allow the rule out of AMI with only baseline measurements, our results provide further proof for the potential of combined measurements to allow a more rapid rule out of AMI.

\section{Acknowledgements}

We thank Ron Mohren for technical assistance.

\section{Declaration of conflicting interests}

$\mathrm{JG}$ is CSO of FABPulous BV.

\section{Funding}

The Jeroen Bosch Academy provided a financial grant to fund part of this study. B.R.A.H.M.S and Siemens provided the copeptin and cTnI assays (kits) for this study at a reduced price. FABPulous BV funded the H-FABP measurements.

\section{Ethical approval}

Not applicable.

\section{Guarantor}

RK.

\section{Contributorship}

LJ, MB, EG, ME, MD and RK conceived the study and were involved in gaining ethical approval and together with BS and $\mathrm{JG}$ were involved in protocol development and data analysis. ME, BS and MD were involved in patient recruitment. All authors contributed to the data retrieval and analysis. LJ and MB wrote the first draft of the manuscript. All authors reviewed and edited the manuscript and approved the final version.

\section{References}

1. Go AS, Mozaffarian D, Roger VL, et al. Heart disease and stroke statistics - 2013 update: a report from the American Heart Association. Circulation 2013; 127: e6-e245.

2. Mehta SR, Granger CB, Boden WE, et al. Early versus delayed invasive intervention in acute coronary syndromes. New Engl J Med 2009; 360: 2165-2175.

3. Keller T, Tzikas S, Zeller $\mathrm{T}$, et al. Copeptin improves early diagnosis of acute myocardial infarction. $J \mathrm{Am}$ Coll Cardiol 2010; 55: 2096-2106.

4. Reichlin T, Hochholzer W, Stelzig C, et al. Incremental value of copeptin for rapid rule out of acute myocardial infarction. J Am Coll Cardiol 2009; 54: 60-68.

5. Goodacre S, Thokala P, Carroll C, et al. Systematic review, meta-analysis and economic modelling of diagnostic strategies for suspected acute coronary syndrome. Health Tech Assess (Winchester, England) 2013; 17: v-vi, 1-188.

6. Morrow DA, Cannon CP, Jesse RL, et al. National academy of clinical biochemistry laboratory medicine practice guidelines: clinical characteristics and utilization of biochemical markers in acute coronary syndromes. Clin Chem 2007; 53: 552-574.

7. Thygesen K, Alpert JS, Jaffe AS, et al. Third universal definition of myocardial infarction. J Am Coll Cardiol 2012; 60: 1581-1598.

8. Forberg JL, Henriksen LS, Edenbrandt L, et al. Direct hospital costs of chest pain patients attending the emergency department: a retrospective study. BMC Emerg Med 2006; 6: 6 .

9. Kleine AH, Glatz JF, Van Nieuwenhoven FA, et al. Release of heart fatty acid-binding protein into plasma after acute myocardial infarction in man. Mol Cell Biochem 1992; 116: 155-162.

10. Bruins Slot MH, Reitsma JB, Rutten FH, et al. Hearttype fatty acid-binding protein in the early diagnosis of acute myocardial infarction: a systematic review and meta-analysis. Heart (British Cardiac Society) 2010; 96: 1957-1963.

11. Lippi G, Mattiuzzi C and Cervellin G. Critical review and meta-analysis on the combination of heart-type fatty acid binding protein (H-FABP) and troponin for early diagnosis of acute myocardial infarction. Clin Biochem 2013; 46: $26-30$. 
12. Katan M, Morgenthaler N, Widmer I, et al. Copeptin, a stable peptide derived from the vasopressin precursor, correlates with the individual stress level. Neuro Endocrinol Lett 2008; 29: 341-346.

13. Potocki M, Reichlin T, Thalmann S, et al. Diagnostic and prognostic impact of copeptin and high-sensitivity cardiac troponin $\mathrm{T}$ in patients with pre-existing coronary artery disease and suspected acute myocardial infarction. Heart (British Cardiac Society) 2012; 98: 558-565.

14. Karakas M, Januzzi JL Jr., Meyer J, et al. Copeptin does not add diagnostic information to high-sensitivity tropo$\operatorname{nin} \mathrm{T}$ in low- to intermediate-risk patients with acute chest pain: results from the rule out myocardial infarction by computed tomography (ROMICAT) study. Clini Chem 2011; 57: 1137-1145.

15. Maisel A, Mueller C, Neath SX, et al. Copeptin helps in the early detection of patients with acute myocardial infarction: primary results of the CHOPIN trial (copeptin helps in the early detection of patients with acute myocardial infarction). J Am Coll Cardiol 2013; 62: 150-160.

16. Wodzig KW, Pelsers MM, van der Vusse GJ, et al. Onestep enzyme-linked immunosorbent assay (ELISA) for plasma fatty acid-binding protein. Ann Clin Biochem 1997; 34(Pt 3): 263-268.

17. Glatz JF and Mohren R. Plasma reference value of hearttype fatty acid-binding protein, the earliest available plasma biomarker of acute myocardial infarction. Health (1949-4998) 2013; 5: 1206-1209.

18. DeLong ER, DeLong DM and Clarke-Pearson DL. Comparing the areas under two or more correlated receiver operating characteristic curves: a nonparametric approach. Biometrics 1988; 44: 837-845.

19. Raskovalova T, Twerenbold R, Collinson PO, et al. Diagnostic accuracy of combined cardiac troponin and copeptin assessment for early rule-out of myocardial infarction: a systematic review and meta-analysis. Eur Heart J: Acute Card Care 2013. DOI: 10.1177/ 2048872613514015.

20. Collinson P, Gaze D and Goodacre S. Comparison of contemporary troponin assays with the novel biomarkers, heart fatty acid binding protein and copeptin, for the early confirmation or exclusion of myocardial infarction in patients presenting to the emergency department with chest pain. Heart (British Cardiac Society) 2014; 100: 140-145.

21. Sebbane M, Lefebvre S, Kuster N, et al. Early rule out of acute myocardial infarction in ED patients: value of combined high-sensitivity cardiac troponin $\mathrm{T}$ and ultrasensitive copeptin assays at admission. Am J Emerg Med 2013; 31: $1302-1308$.

22. Ruff CT, Bonaca MP, Kosowsky JM, et al. Evaluation of the diagnostic performance of heart-type fatty acid binding protein in the BWH-TIMI ED chest pain study. J Thromb Thrombolysis 2013; 36: 361-367.

23. Reiter M, Twerenbold R, Reichlin T, et al. Heart-type fatty acid-binding protein in the early diagnosis of acute myocardial infarction. Heart (British Cardiac Society) 2013; 99: 708-714. 